\title{
Chinese and English Psychiatric Nurses' Attitudes on Schizophrenia
}

Graham Thornicroft, Registrar, Maudsley Hospital, Denmark Hill, London SE5 (correspondence) and Tom TraUER, District Clinical Psychologist, King's College Hospital, Denmark Hill, London SE5

In parallel with more open political access for Westerners to China over the last decade, there has been a proliferation of interest in Chinese psychiatry. The pre- and post-liberation developments of the specialty have been reviewed. ${ }^{1.2 .3}$ Further, increasingly detailed and balanced first-hand accounts by Western psychiatrists of visits to Chinese facilities have appeared. ${ }^{4}$

As yet there have been few comparative studies of Chinese and Western psychiatric theories and practices. The perceptions of Chinese residents in Hong Kong towards Chinese and Western forms of treatment have been compared. ${ }^{5} \mathrm{~A}$ recent Shanghai study has shown the content of the delusions of schizophrenic patients to be contextspecific, and markedly different from classical Western urban descriptions. ${ }^{6}$

Diagnostic differences have hitherto limited valid comparisons between Chinese and Western psychiatric research. There is evidence however that the Traditional Chinese Medicine (TCM) diagnosis of schizophrenia appreciably overlaps with those of the West. Dr Chen Chang Hui of the Beijing Mental Health Institute has studied 98 patients diagnosed as schizophrenic by TCM standards. Of these, 82 satisfied the ICD 9 requirements, and 84 satisfied the DSM III criteria for such a diagnosis. Future research may be facilitated by the recently developed Chinese version of the Diagnostic Interview Schedule.

This paper describes a study comparing the attitudes towards schizophrenia of psychiatric nurses from four hospitals, two in China and two in England. Nurses were chosen as the staff group studied in order to provide sufficient respondents for statistical analysis, and because they occupy a well defined and similar role in the two countries. The study was conducted on the basis that the nurses' attitudes elicited would reflect both their theoretical teaching and their clinical experience.

\footnotetext{
Method

The objective of this cross-sectional study was to investigate the attitudes to schizophrenia of psychiatric nurses from two Chinese and two English hospitals. The age, sex, status and experience of each respondent was requested. The hypothesis under test was that there were no significant differences between the responses of the two national nursing samples. The hospitals chosen for the study were Guy's Hospital in London, Oakwood Hospital in Maidstone, the Shanghai Psychiatric Institute and the Mental Health Institute of the Beijing Medical College. The questionnaires were given to the psychiatric nursing officer in each hospital, who was asked to distribute them to an alphabetical interval sample of the total available psychiatric nursing popu-
}

lation. The number of respondents (in relation to the total number of questionnaires distributed) in each hospital was: Guy's 28/35 (80\%), Oakwood 60/140 (43\%), Beijing 31/46 $(67 \%)$, and Shanghai 64/68 (94\%).

The questionnaire items were designed by one author (GT) to cover the main ideas current within Western and traditional Chinese medicine on the aetiology, presentation, treatment and prognosis of schizophrenia. Of the 34 items, half were phrased in the negative to minimise the response bias. Two questions were phrased in both positive and negative ways to test internal reliability. In each item the subject chose one from six possible ordinal responses labelled: I strongly disagree, I disagree pretty much, I disagree a little, I agree a little, I agree pretty much and I strongly agree. Non responses were excluded from the analysis. Each respondent received a covering letter with the questionnaire stating the identity of the author, the nature of the enquiry and the confidential nature of the responses. The Chinese translation used was made by a Chinese-speaking psychologist, drawing upon two separate draft translations, and was back-translated to test the accuracy of the Chinese version.

Analysis of the data used first the two-tailed Student's $t$ test for differences between the mean response scores of the two national nursing groups. Second, a discriminant function analysis was performed to separate the total number of respondents into the Chinese and English subgroups, on the basis of responses to a limited subset of items.

\section{Results}

Of the returned questionnaires, $94 \%$ contained complete responses to the demographic items. The respondents, all psychiatric nurses, showed a very similar age structure between the two national groups: $54 \%$ of the English sample and $58 \%$ of the Chinese sample were aged between 26 and 40, the remainder being split equally between those who were older and younger. The overall proportion of male nurses in the English respondents was twice that of the Chinese, but with considerable variation between centres (Oakwood 53\% male, Guy's 25\%, Beijing 32\%, Shanghai $16 \%)$. The structure of the professional roles of the respondents was influenced by two factors: a greater proportion of charge nurses in both English groups (30\% overall compared with $8 \%$ of the Chinese nurses), and student nurses only substantially represented at Guy's Hospital. It was this latter group of nursing students which increased the proportion of English respondents with less than six years of psychiatric nursing experience to $43 \%$, twice the Chinese proportion, whereas twice as many Chinese nurses (26\%) had more than 15 years psychiatric experience. 
Of the 34 questionnaire items, 19 showed a significant difference between the means of the responses of the Chinese and English groups. The significance level was set at $\mathbf{0 . 0 2 5}$ for a two-tailed Student's $t$ test. For these items the null hypothesis was rejected.

Among the items which showed significant differences, the Chinese respondents were more likely to agree that the cause of schizophrenia is related to biochemical, infective and genetic factors. They were significantly less likely to view past life events as causal. Regarding treatment, the Chinese respondents favoured ECT, acupuncture, and herbal remedies. The Chinese nurses saw the presentation of schizophrenia more in terms of incomprehensible talk, criminal (but not violent) behaviour, unusual mood changes, and sleep disturbance. In terms of prognosis, the Chinese group agreed significantly more often that schizophrenic patients could not go on to full employment, should neither marry nor have children, and could expect their condition to become steadily worse.

A stepwise discriminant function analysis was used to separate the English and Chinese groups on the basis of their responses to the questionnaire items. The answers to five items (regarding ECT, employment prospects, sexual aetiology, tendency to violence, and poor overall prognosis) were sufficient to classify correctly into national groups 140 of the $156(90 \%)$ respondents included in the analysis. By comparison, when the stepwise procedure progressed to include 19 questions, these distinguished between $93 \%$ of the total sample. The internal reliability of the instrument was confirmed by the results of the two pairs of repeated items.

\section{Discussion}

In examining views on the causation of schizophrenia this study has showed that Chinese respondents were signifcantly more likely to favour physical explanations, including biochemical, genetic, and infective factors. They were less likely to support social, psychological and psychoanalytical views than the English nurses questioned. These results may be seen to represent a marked movement away from views prevalent in China towards the end of the Cultural Revolution. At that time the causes of mental illness were analysed within political terms in relation to the persistence of social class contradictions. English respondents were significantly more likely to see past life events as implicated in the aetiology of schizophrenia, and this view incorporates both the relative importance attributed within Western psychiatry to the clinical history and the acceptance of life events as significant predisposing and precipitating factors in the development of mental disorder.

As mentioned earlier, the diagnostic features of schizophrenia identified by the Chinese nurses in this study were characteristically behavioural changes: sleep disturbance, unusual mood changes, and criminality (but not violence). This may be interpreted in two senses: first that nurses in China have less basic training in psychiatric concepts than their counterparts in England; second, the Chinese focus upon the behaviour of these patients is consistent with their view that the talk of schizophrenic patients is incomprehensible. An exception to this pattern was the significantly greater attention paid by the English respondents to violence. In the Confucian tradition violence is legitimate only in the pursuit of righteousness, and physical confrontation is much less a part of everyday life than in England.

On the treatment of schizophrenia, firm agreement existed between the Chinese and English respondents upon the efficacy of antipsychotic drugs. Where there was significant disagreement, the English respondents favoured individual psychotherapy and occupational therapy, where the Chinese nurses regarded ECT, acupuncture and herbal remedies more favourably. By comparison, 20 years earlier ECT (and along with it psycho-surgery) had been abandoned as 'bourgeois methods' and was only selectively re-introduced, usually in its unmodified form without anaesthesia, after 1976. Individual psychotherapy was significantly less favourably rated by the Chinese nurses. Indeed, throughout this century Freudian psychotherapy has failed to exert any substantial influence and in the period since Liberation in 1949 the concept of the unconscious has found no place within Chinese political, social and psychiatric thought.

English nurses' views on the prognosis of schizophrenia were characterised by guarded optimism that, although full recovery was unlikely, full employment was a strong possibility. The Chinese attitudes studied were significantly different: schizophrenic patients should not marry, should not have children and could be expected to become steadily worse. This directly contradicts the 'revolutionary optimism' of the Cultural Revolution when it was asserted that 'the patient will have a bright future'. Indeed these results demonstrate both therapeutic pessimism and authoritarianism. This latter element is consistent with the results of a study of attitudes towards mental illness in Great Britain, Czechoslovakia and West Germany which found that such attitudes were more related to general orientation towards social issues than to a narrow conception of mental illness. The inference was drawn that authoritarian attitudes to mental illness would be more prevalent in a community characterised by an authoritarian socialpolitical structure. $^{8}$

A number of criticisms may be levelled at this study. In view of the small number of nurses and hospitals involved, no claim can be made that they are representative of English and Chinese nurses in general. Further, the accuracy of the translation of the questionnaire, although the product of three Chinese speakers, may be called into question. The two nursing groups were not closely matched for sex and role, although age and experience were comparable. The response rate at Oakwood Hospital was $43 \%$, compared with at least $67 \%$ in the other samples. This may relate to a separate survey carried out at this hospital shortly before this study, the results of which nursing staff felt might be used against their interests. Although liaison with the English nursing officers ensured a satisfactory interval sample of all grades of nursing staff, it was not possible to check that the Chinese nursing officers had followed 
the same procedure, and interpretations based upon the Chinese data must be guarded.

The emphasis of this study was upon staff attitudes and not upon behaviour. A review of the relationship between expressed attitudes and overt behaviour found a correlation of 0.30 or less. ${ }^{9}$ Indeed the relationship may be inverse: a survey of attitudes toward the mentally ill in a rural Canadian town suggested that those with more 'enlightened' attitudes may manifest less tolerant behaviour. ${ }^{10}$ Staff attitudes may however be related to therapeutic outcome. Wing's study of 20 chronic schizophrenic patients at an Industrial Rehabilitation unit suggested that consistently high staff expectations were associated with improved prognosis. ${ }^{11}$ Cohen and Struening, using the Opinions about Mental Illness scales, have shown that authoritarianism in staff attitudes may be related to longer admission. ${ }^{12}$

In conclusion, this first comparative report on the attitudes of Chinese and English psychiatric staff towards schizophrenia has shown significant attitudinal differences. The Chinese nurses questioned were characteristically more pessimistic and authoritarian. Conversely there was also agreement upon the value of anti-psychotic medication, and upon the relapsing nature of schizophrenia, producing an impoverished level of social and emotional function. No society is static, and from the perspective of Western practitioners looking Eastwards, the change in attitudes toward mental illness in China over the decade since the end of the Cultural Revolution has been remarkably rapid as the pendulum has swung from ideological to biochemical and genetic accounts of aetiology, while retaining the therapeutic uses of Traditional Chinese Medicine.

\section{ACKNOWLEDGEMENTS}

The authors wish to thank the staff of Oakwood Hospital, Guy's Hospital, The Mental Health Institute of the Beijing Medical College, and the Shanghai Psychiatric Institute who participated in this study, as well as Professor J. P. Watson and his colleagues in the Department of Psychiatry, United Medical Schools (Guy's Campus).

\section{REFERENCES}

${ }^{1}$ HiLlier, S. (1983) Psychiatry and the treatment of mental illness in China. In Health Care and Traditional Medicine in China 1800-1982. S. Hillier \& J. Jewell. London: Routledge \& Kegan Paul.

${ }^{2}$ Lin, T. Y. \& EISENBERG, L. (1985) Mental Health Planning for One Billion People, a Chinese Perspective. Vancouver: University of British Columbia Press.

${ }^{3}$ Livingston, M. \& Lowinger, P. (1983) The Minds of the Chinese People-Mental Health in New China. Englewood Cliffs, New Jersey: Prentice Hall.

4PArry-Jones, W. Ll. (1986) Psychiatry in the People's Republic of China. British Journal of Psychiatry, 148, 632-641.

${ }^{5}$ LEE, R. (1980) Perceptions and uses of Chinese medicine among the Chinese in Hong Kong. Culture, Medicine and Psychiatry, 4, 345-375.

${ }^{6} \mathrm{Hsia}$ YU Fen \& TsiaI Neng (1981) Transcultural investigation of recent symptomatology of schizophrenia in China. American Journal of Psychiatry, 138, 1484-1486.

${ }^{7}$ HwU, H. G., YeH, E. K. \& Chang, L. Y. (1986) Chinese Diagnostic Interview Schedule. Acta Psychiatrica Scandinavica, 73, 225-233.

${ }^{8}$ LEVINE, D. (1972) A cross-national study of attitudes towards mental illness. Journal of Abnormal Psychology, 80, 111-114.

${ }^{9}$ WiCKER, A. (1969) Attitudes versus actions: the relationship between verbal and overt behavioural responses to attitude objects. Journal of Social Issues, 25, 41-78.

${ }^{10}$ RoOtman, I. \& LAFAVE, H. (1969) Are popular attitudes towards the mentally ill changing? American Journal of Psychiatry, 126, 261-265.

${ }^{11}$ WING, J. (1961) Attitudes to the employability of chronic schizophrenic patients. Occupational Psychology, 36, 58-64.

${ }^{12}$ Cohen, J. \& STruennng, E. (1962) Opinions about mental illness in the personnel of two large mental hospitals. Journal of Abnormal Psychology, 64, 349-360.

\section{Workshops}

The Association for Family Therapy will be holding their Annual Training Meeting at the University of York from 10-12 September 1987. Those interested in submitting a workshop of either three or six hours should contact the Conference Organiser: Dr Michael Sevitt, 7 Upper Park Road, Kingston upon Thames KT2 5LB (telephone 01546 4173). Closing date: 1 May 1987.

A research workshop is being held this year. For further information please contact Dr Michael Sevitt (see above) or Dr Ivan Eisler (01 7035411 , extension 303). Closing date: 1 June 1987.

A one-day MRCPsych Final Examination workshop will be held on 7 April 1987 at the Kingsway Hospital, Derby. For further information and application form contact $\mathrm{Dr}$ H. Ghadiali or Dr M. A. Zaman at the Kingsway Hospital (telephone 0332 36221). 